\title{
Expression of Livin and PIGF in human osteosarcoma is associated with tumor progression and clinical outcome
}

\author{
KUO SUN $^{1}$, QI LIAO ${ }^{1}$, ZENGGAN CHEN $^{2}$, TONGYI CHEN ${ }^{2}$ and JIAN ZHANG ${ }^{2}$ \\ ${ }^{1}$ Department of Orthopedics, The Second Affiliated Hospital of Nanchang University, Nanchang, Jiangxi 330006; \\ ${ }^{2}$ Department of Orthopedics, Zhongshan Hospital, Fudan University, Shanghai 200032, P.R. China
}

Received May 25, 2016; Accepted August 10, 2017

DOI: $10.3892 / 01.2018 .9239$

\begin{abstract}
Baculoviral IAP repeat containing 7 (BIRC7/Livin/ML-IAP/KIAP; referred to as Livin throughout the present study) and placental growth factor (PlGF) are not detectable in the majority of normal differentiated tissues, but are present in a number of types of cancer, including hepatocellular carcinoma, ovarian cancer and renal cell carcinoma. The aim of the present study was to assess the expression levels of Livin and PlGF in human osteosarcoma specimens and cell lines, and to analyze the functions of Livin and PIGF in the prognosis of osteosarcoma. The expression levels of Livin and PlGF in 48 osteosarcoma specimens and three osteosarcoma cells were determined using immunohistochemistry and reverse transcription-quantitative polymerase chain reaction. The positivity rates of Livin and PlGF in osteosarcoma specimens were 58.3 and $60.4 \%$, respectively, but were $0 \%$ in normal bone tissues. The expression levels of Livin and PIGF were increased in MG-63 cells, compared with those in the other cell lines evaluated in the present study. In addition, the expression levels of Livin and PIGF were significantly associated with tumor diameter and Enneking staging, but were independent of tumor site, age and sex of patients. The expression level of Livin was not associated with PIGF. Furthermore, the 5-year overall survival rate was decreased in the Livin or PlGF expression group, compared with that in the non-expression group $(\mathrm{P}=0.034$ and $\mathrm{P}=0.012$, respectively). The expression levels of Livin and PlGF were independent prognostic factors for patients with osteosarcoma. The results of the present study demonstrated that Livin and PlGF may participate in the pathogenesis of osteosarcoma.
\end{abstract}

Correspondence to: Professor Jian Zhang, Department of Orthopedics, Zhongshan Hospital, Fudan University, 180 Fenglin Road, Shanghai 200032, P.R. China

E-mail: zhang.jian@zs-hospital.sh.cn

Professor Qi Liao, Department of Orthopedics, The Second Affiliated Hospital of Nanchang University, 1 Minde Road, Nanchang, Jiangxi 330006, P.R. China

E-mail: liaoqi@medmail.com.cn

Key words: osteosarcoma, Livin, placental growth factor, prognosis
Therefore, pharmacological inhibition of Livin or PlGF may provide a novel strategy for osteosarcoma treatment.

\section{Introduction}

Osteosarcoma is the most common type of primary bone sarcoma in teenagers and represents the second highest cause of cancer-associated mortality in this age group worldwide (1). At present, the treatment of osteosarcoma consists of preoperative chemotherapy, followed by wide surgical resection and a postoperative chemotherapy regimen, modified according to the proportion of necrotic cells (2). However, in spite of the advancements in early detection and combined therapy strategies, the prognosis for patients with osteosarcoma remains poor, and between 30 and $40 \%$ all patients develop lung metastasis, which is the primary cause of mortality from this disease (3). In addition, the majority of chemotherapeutics exhibit the risk of short- and long-term toxic effects. The emerging knowledge of the pathogenesis and genetic abnormalities associated with osteosarcoma has exposed the field to new potential molecular targets (4).

Baculoviral IAP repeat containing 7 (termed Livin) is a novel member of the inhibitor of apoptosis proteins (IAPs) family, which controls the basal level of apoptosis in mammalian cells (5). The expression of Livin is associated with aggressive disease and poor clinical outcome in patients with osteosarcoma (6). Tumor growth and metastasis are dependent on the degree of neovascularization, which is regulated by pro-angiogenic and anti-angiogenic factors. Vascular endothelial growth factor (VEGF) is an important angiogenic factor and has been studied most extensively in a number of types of cancer, including breast cancer and renal cell carcinoma $(7,8)$. Previous studies have demonstrated that VEGF stimulation may increase Livin expression and induce the pathogenesis of human esophageal carcinoma and cervical cancer $(9,10)$. Placenta growth factor (PlGF) is a dimeric glycoprotein, and is structurally and functionally associated with VEGF (11). PIGF is not produced by the majority of types of normal human tissue and serves a function in pathological angiogenesis (12). In addition, it has been revealed that PIGF secretion in MG-63 osteosarcoma cells was induced by bone morphogenetic protein-2, and led to the paracrine regulation of angiogenesis and hemopoiesis in bone formation (13). To date, the expression of PIGF in osteosarcoma and any association between 
PIGF and Livin remains unknown. On the basis of previous studies $(14,15)$, the present study examined the expression levels of Livin and PIGF in human osteosarcoma tissues and osteosarcoma cells, and analyzed their associations and prognostic values in osteosarcoma.

\section{Materials and methods}

Cell culture. Human osteosarcoma cell lines (U2OS, SaOS-2 and MG-63) purchased from the Cell Bank of Chinese Academy of Science (Shanghai, China) were cultured in Dulbecco's modified Eagle's medium (Gibco; Thermo Fisher Scientific, Inc., Waltham, MA, USA), supplemented with $10 \%$ fetal bovine serum (Gibco; Thermo Fisher Scientific, Inc.). All cell lines were maintained in an atmosphere of $5 \% \mathrm{CO}_{2}$ with humidity at $37^{\circ} \mathrm{C}$.

Patients and tissue samples. The present study was retrospective. Human osteosarcoma specimens were obtained from 48 patients with osteosarcoma between Enneking's stages IB and III. The present study was approved by the institutional review board of Zhongshan Hospital (Shanghai, China) and all aspects of the study comply with the Declaration of Helsinki. As this is a retrospective study, the Ethics Committee approved that informed consent was not required because data would be analyzed anonymously. However, the patients or their guardians signed informed consent for biopsy or tumor excision surgery. No patients received pre-surgical chemotherapy or radiotherapy. Specimens were fixed at $4{ }^{\circ} \mathrm{C}$ in $10 \%$ formalin-buffered solution for $24 \mathrm{~h}$, embedded in paraffin and cut into $5-\mu \mathrm{m}$ tissue sections prior to immunohistochemistry. A total of 30 males and 18 females were included in the present study, with a mean age of 22.6 years (range, 6-72 years). According to Enneking's staging (16), 17 patients were staged between IB and IIA, and the remaining 31 patients were staged between IIB and IIIB (16). The tumors were located on the distal femur in 27 patients, proximal tibia in 7 patients, proximal fibula in 2 patients, proximal humerus in 7 patients and at other sites (vertebra, pelvis and tarsus) in 5 patients (Table I). The histological type of osteosarcoma was osteoblastic, chondroblastic and fibroblastic in 29, 11 and 8 patients, respectively, which was determined by the combination of imaging manifestation, clinical manifestation and pathological features. There were 30 cases with a tumor diameter $\leq 5 \mathrm{~cm}$ and a total of 18 cases exhibited a tumor diameter $>5 \mathrm{~cm}$. A total of 10 normal bone tissue samples were selected from 3 male and 7 female healthy donors, with a mean age of 61.1 years (range, 55-64 years) who had undergone total knee arthroplasty from Jan 2013 to Dec 2014 at the Zhongshan Hospital. The samples were frozen in liquid nitrogen at $-196^{\circ} \mathrm{C}$ immediately following excision and then cut into $5-\mu \mathrm{m}$ tissue sections. Protocols were approved by the Institutional Review Boards of Zhongshan Hospital and each patient in the healthy controls group provided written informed consent for total knee arthroplasty surgery. Clinical data were obtained from the medical records. Follow-up time was calculated from the date of surgery to the death of the patient or 5 years after surgery.

Immunohistochemistry (IHC). All samples were decalcificated prior to IHC. The expression of Livin and PIGF was determined by IHC. Sections were stained with rabbit polyclonal anti-human Livin (PAB12872) and PlGF (PAB8004) primary antibodies (1:100 dilutions; Abnova, Taipei, Taiwan) for $12 \mathrm{~h}$ at $4^{\circ} \mathrm{C}$ and then horseradish peroxidase-conjugated goat polyclonal anti-rabbit secondary antibody (31460; 1:5,000 dilution; Thermo Fisher Scientific, Inc.) for $20 \mathrm{~min}$ at $37^{\circ} \mathrm{C}$, according to the manufacturer's protocol. Bone samples were used as negative controls for Livin and PlGF staining. The expression was evaluated independently by two pathologists and the data from the two investigators were averaged. Under the light microscope, positive cells were observed as cells containing brown granules in the nucleus or cytoplasm. For each section, a charge-coupled device camera was used to capture at least five fields of view at magnification x400 (Olympus BX51 CCD; P70; Olympus Corporation, Tokyo, Japan). Image-Pro Plus software (version 5.0; Media Cybernetics, Inc., Rockville, MD, USA) was used to quantitatively analyze the images. The score was calculated by summing the intensity score and the proportion score, providing a score between 0 and 9 . The proportion score was calculated as follows: 0 , no positivity; +1 , $\leq 25 \%$ tumor cell positivity; $+2,26-50 \%$ tumor cell positivity; and $+3,>50 \%$ tumor cell positivity. The intensity score was calculated as follows: 0 , no staining; +1 , weak staining; +2 , intermediate staining; and +3 , strong staining. Specimens were additionally divided into a low or high expression group, according to their score as follows: Specimens with score $\leq 2$ were regarded as low expression; and specimens with scores $>2$ were regarded as high expression (17).

Reverse transcription-quantitative polymerase chain reaction $(R T-q P C R)$. Total RNA was isolated from osteosarcoma cells (MG-63, Saos-2 and U-OS) with TRIzol reagent (Thermo Fisher Scientific, Inc.) and reverse-transcribed to synthesize cDNA using a PrimeScript 1st Strand cDNA Synthesis kit (Takara Biotechnology Co., Ltd., Dalian, China) according to the manufacturer's protocol. qPCR assay was conducted using a TaqMan ${ }^{\circledR}$ One-Step PCR Master Mix (Applied Biosystems; Thermo Fisher Scientific, Inc.), according to the following protocol: 40 cycles consisting of denaturation at $95^{\circ} \mathrm{C}$ for $5 \mathrm{sec}$, annealing at $60^{\circ} \mathrm{C}$ for $30 \mathrm{sec}$, and extension at $72^{\circ} \mathrm{C}$ for $30 \mathrm{sec}$. A standard curve was generated on the basis of a linear association between the first cycle number at which the fluorescence signal significantly increased [quantification cycle $(\mathrm{Cq})$ value] and the logarithm of the initial value. The quantity of target mRNA in unknown samples was determined from the $\mathrm{Cq}$ value using a standard curve. A control without template was included in each experiment. Non-template and DNA controls, standard dilutions, and samples were assayed in duplicate. The expression levels of Livin and PIGF mRNA were normalized to that of GAPDH mRNA, and divided into high and low expression groups. GAPDH primers were as follows: Forward, 5'-GCACCGTCAAGGCTGAGAAC-3'; and reverse, 5'-TGGTGAAGACGCCAGTGGA-3'. Equal volumes of complementary DNA from each sample were amplified using the following primers: Livin forward, 5'-AAGGAAGAG ACTTTGTCCACAGTGT-3'; Livin reverse, 5'-GGCTGCGTC TTCCGGTT-3'; PIGF forward, 5'-TCAGAGGTGGAAGTG GTA-3'; and PIGF reverse, 5'-ACACAGTGCAGATTCTCA-3'. Two independent experiments were performed in triplicate, and the PCR products were measured using an ABI PRISM 
Table I. Association between the expression of Livin and PIGF and the clinicopathological characteristics of patients with osteosarcoma.

\begin{tabular}{|c|c|c|c|c|c|}
\hline Characteristic & $\mathrm{n}$ & Livin positive, $\mathrm{n}(\%)$ & P-value & PlGF positive, n (\%) & P-value \\
\hline Cases & 48 & $28(58.3)$ & & $29(60.4)$ & \\
\hline Sex & & & 0.762 & & 0.594 \\
\hline Male & 30 & $17(56.7)$ & & $19(63.3)$ & \\
\hline Female & 18 & $11(61.1)$ & & $10(55.6)$ & \\
\hline Age, years & & & 0.922 & & 0.863 \\
\hline$\leq 20$ & 26 & $15(57.7)$ & & $16(61.5)$ & \\
\hline$>20$ & 22 & $13(59.1)$ & & $13(59.1)$ & \\
\hline Tumor site & & & 0.883 & & 0.315 \\
\hline Femur & 27 & $16(59.3)$ & & 18 (66.7) & \\
\hline Tibia fibula & 9 & $6(66.7)$ & & $6(66.7)$ & \\
\hline Humerus & 7 & $4(57.1)$ & & $4(57.1)$ & \\
\hline Others & 5 & $2(40.0)$ & & $1(20.0)$ & \\
\hline Enneking stage & & & 0.003 & & $<0.001$ \\
\hline IB-IIA & 17 & $5(29.4)$ & & $4(23.5)$ & \\
\hline IIB-III & 31 & $23(74.2)$ & & 25 (80.6) & \\
\hline Tumor diameter, $\mathrm{cm}$ & & & 0.007 & & 0.047 \\
\hline$\leq 5$ & 30 & $13(43.3)$ & & $16(53.3)$ & \\
\hline$>5$ & 18 & $15(83.3)$ & & $13(72.2)$ & \\
\hline
\end{tabular}

Livin, baculoviral IAP repeat containing 7; PIGF, placental growth factor.

7700 Sequence Detection System (Applied Biosystems; Thermo Fisher Scientific, Inc.) and analyzed with ABI PRISM 7000 SDS v.1.2.3 RQ software (Applied Biosystems; Thermo Fisher Scientific, Inc.).

Statistical analysis. For survival analysis, overall survival (OS) time was defined as the interval between the date of diagnosis and the date of mortality or the last follow-up. All statistical analyses were performed using SPSS software (v.18; SPSS, Inc., Chicago, IL, USA). To analyze the prognostic significance of Livin and PlGF expression, the $\chi^{2}$ test was used to test the association between Livin and PlGF expression level and other prognostic factors. The Kaplan-Meier method was used to estimate curves for OS for the subgroups of potential prognostic factors, and comparisons were conducted using the log-rank test. Univariate and multivariate regression analyses according to the Cox's proportional hazards regression model, with OS as the dependent variable, were used to evaluate Livin and PIGF expression as potential independent prognostic factors. The Cox proportional hazard model was used to analyze data for Livin and PIGF expression against OS time (in months) and patient status (deceased vs. alive). Covariates included Livin and PIGF expression level (as a continuous variable), age at diagnosis, tumor stage (low stages IB-IIA vs. advanced stages IIB-III), and tumor size. Outcome data were derived from a detailed review of patient medical records and oncology clinical chart, and were supplemented by contact with the treating physician, patient and patient family. $\mathrm{P}<0.05$ was considered to indicate a statistically significant difference.

\section{Results}

Expression of Livin or PlGF is increased in osteosarcoma specimens. The associations between the clinicopathological factors and the expression of Livin or PIGF in 48 osteosarcoma tissues are shown in Table I. The expression levels of Livin and PIGF in osteosarcoma specimens were significantly increased, compared with those in normal bone tissues $(\mathrm{P}<0.01)$. Livin and PlGF proteins were consistently detected in $28(58.3 \%)$ and $29(60.4 \%)$ of the 48 osteosarcoma specimens, respectively, but in none of the normal bone tissues (Fig. 1). Livin and PIGF were predominantly identified in a granular pattern in the cytoplasm. In 17 cases (35.4\%), the two proteins were present in the cytoplasm and in 8 cases $(16.7 \%)$ there was no detection of either protein. In addition, using Spearman's correlation coefficient analysis, no association was identified between the expression of Livin and PlGF $(\mathrm{P}=0.960)$.

Expression of Livin or PlGF is increased in OS cell lines. qPCR was performed to determine the mRNA expression levels of Livin and PlGF in three osteosarcoma cell lines (SaOS-2, MG-63 and U2OS). The expression levels of Livin and PlGF genes were determined in three osteosarcoma cell lines, and were markedly increased in MG-63 cells, compared with those in U2OS and SaOS-2 cells (Fig. 2).

Expression of Livin or PlGF is associated with advanced stage osteosarcoma and tumor diameter. The IHC results demonstrated that the expression levels of Livin and PIGF were associated with pathological stage and tumor diameter 

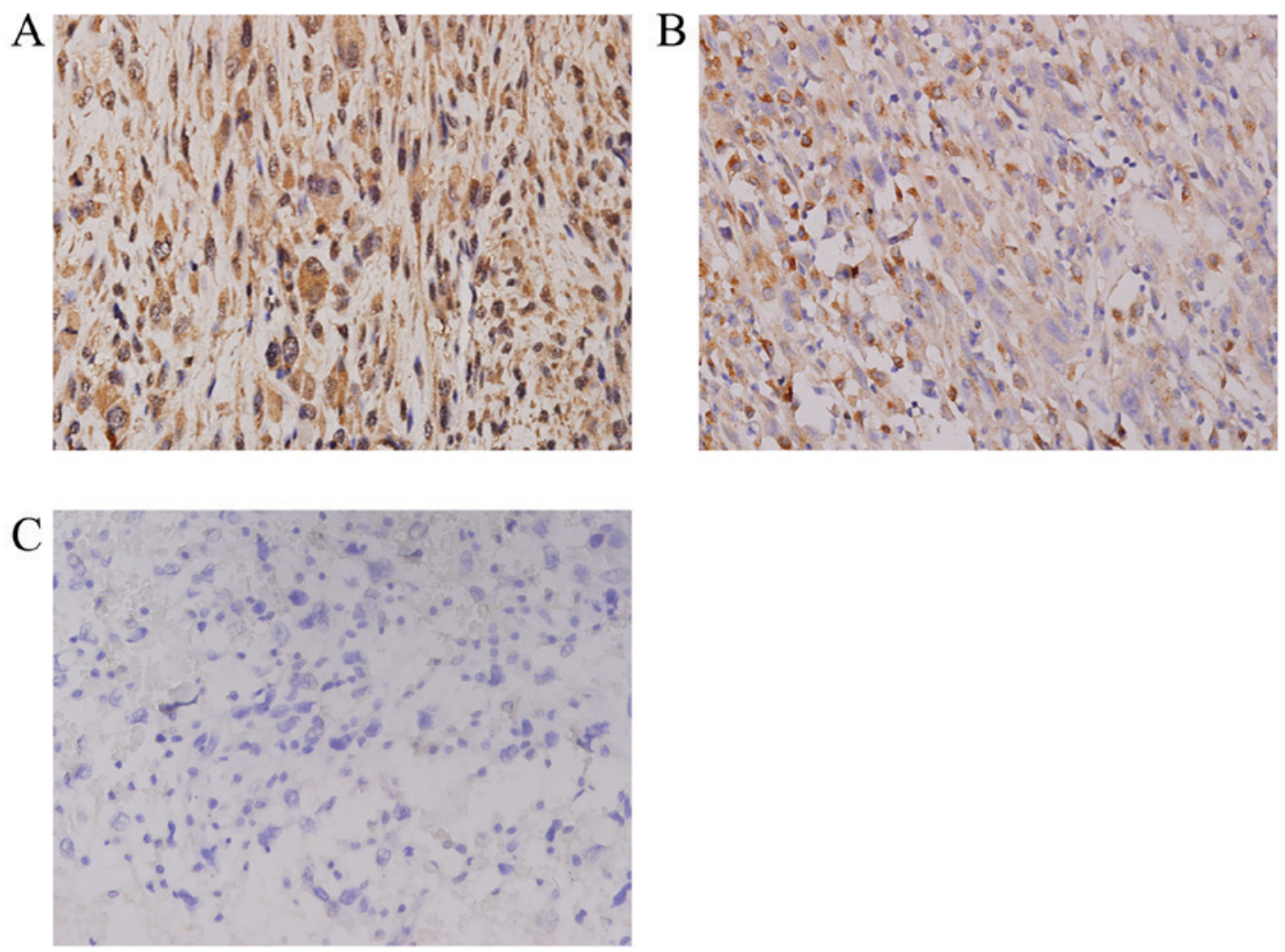

Figure 1. Immunohistochemistry was used to determine the expression of Livin and PIGF in osteosarcoma tissues, compared with that in normal bone tissue. (A) Positive expression of PlGF in osteosarcoma tissue (magnification, $\mathrm{x} 400$ ). (B) Positive expression of Livin in osteosarcoma tissue (magnification, x400). (C) Negative control, normal bone tissue (magnification, $\mathrm{x} 400$ ). Livin, baculoviral IAP repeat containing 7; PIGF, placental growth factor.
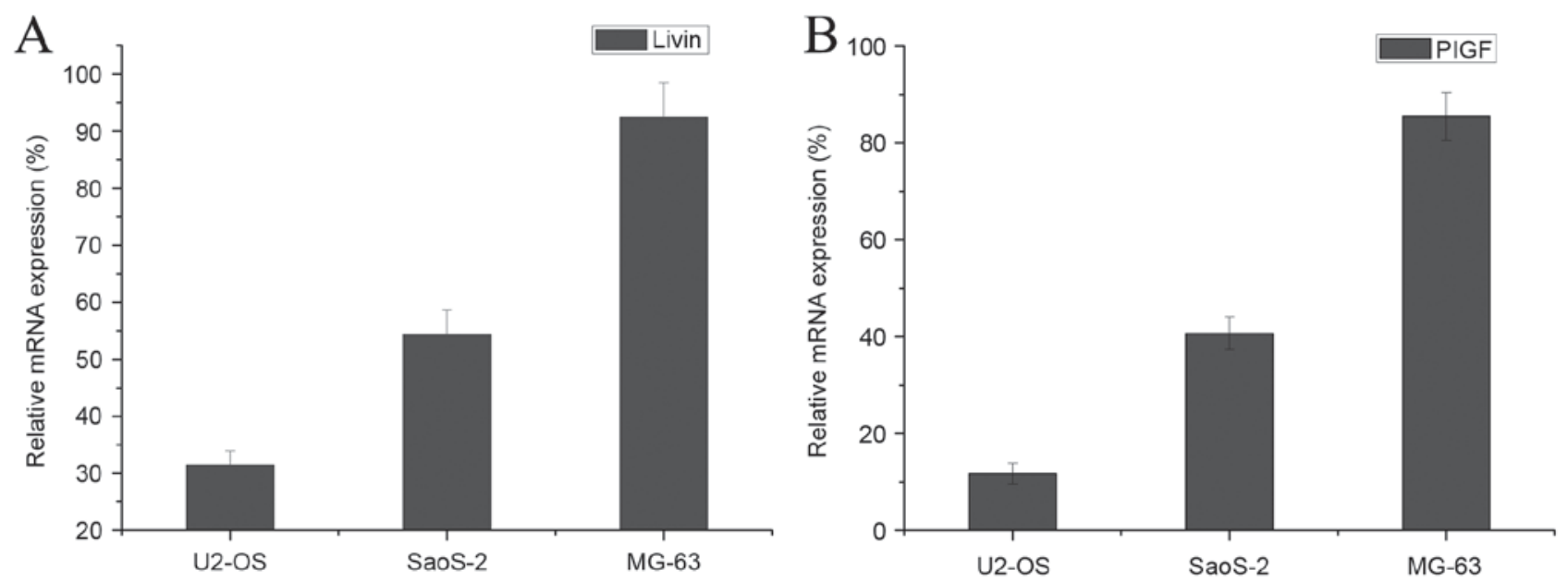

Figure 2. Relative mRNA expression of Livin and PIGF in three osteosarcoma cell lines. The relative mRNA expression of (A) Livin and (B) PlGF, compared with that of GAPDH was determined in U2-OS, SaOS-2 and MG-63 cells. Data are presented as the mean \pm standard deviation. Livin, baculoviral IAP repeat containing 7; PIGF, placental growth factor.

(Table I). The expression levels of Livin and PlGF in patients between stages IB and IIA were significantly decreased, compared with those in patients between stages IIB and III $(\mathrm{P}=0.003$ and $\mathrm{P}<0.001$, respectively). Patients were divided into two groups according to tumor diameter $(\leq 5 \mathrm{~cm}$ and $>5 \mathrm{~cm})$, and the expression levels of Livin and PIGF were compared. There were 30 cases with a tumor diameter $\leq 5 \mathrm{~cm}$, and the positive expression rate of Livin and PIGF was $43.3 \%$ (13 cases) and $53.3 \%$ (16 cases), respectively. A total of 18 cases exhibited a tumor diameter $>5 \mathrm{~cm}$, and the positive expression rate of Livin and PIGF was $83.3 \%$ (15 cases) and $72.2 \%$ (13 cases), respectively. A significant association was identified between the expression levels of Livin or PIGF and tumor diameter ( $\mathrm{P}=0.007$ and $\mathrm{P}=0.047$, respectively). However, there was no significant association between the expression levels of Livin and PIGF and sex, age or site of tumor (Table I). 
Expression of Livin or PlGF is associated with 5-year OS rate. For all of patients in the present study, the median OS time was 73.9 months (range, 18.3-136.5 months) and the 5-year OS rate of the Livin and PIGF high expression group (7 cases, 23.3\%) was significantly decreased, compared with that of the Livin and PIGF low expression group (23 cases, 66.7\%) $(\mathrm{P}=0.003)$. Analysis of the 5-year OS rate revealed a significant difference between patients with tumors exhibiting expression of Livin $(n=28)$ and those with tumors that did not exhibit expression of Livin $(\mathrm{n}=20)(\mathrm{P}=0.034)$. For the 29 patients exhibiting PIGF expression, the survival analysis differed significantly from that of patients who did not express PIGF $(\mathrm{P}=0.012)$ (Table II). Patients with osteosarcoma with low Livin or PIGF expression exhibited a significantly increased survival time, compared with that of patients with high Livin or PlGF expression (Fig. 3).

To assess whether the prognostic value of Livin or PlGF was attributable to prognosis, Cox's regression analysis was performed with all variables including Livin expression, PIGF expression, Livin and PIGF expression, age at diagnosis, tumor stage (low stages IB-IIA vs. advanced stages IIB-III), and tumor size. Univariate analysis revealed that pathological stage and tumor diameter were significant factors influencing the OS time of patients with osteosarcoma. The OS time in patients with stages IB-IIA and a tumor diameter $\leq 5 \mathrm{~cm}$ was significantly increased, compared with that of patients with stages IIB-III and a tumor diameter $>5 \mathrm{~cm}$. Patients exhibiting low Livin and PlGF expression had a markedly longer OS time when compared with that of patients with high Livin and PlGF expression. No significant differences in OS time were observed in any other clinicopathological parameters, including sex, age and tumor site.

Factors that demonstrated prognostic significance by univariate analysis were subsequently examined in a multivariate analysis. A poor OS was identified in patients with high expression of Livin $[\mathrm{P}=0.023$; hazard ratio (HR), 0.274 ; $95 \%$ confidence interval (CI), 0.089-0.839] and PIGF ( $\mathrm{P}=0.014$; HR, 0.209; 95\% CI, 0.060-0.728) ( $\mathrm{P}=0.001 ; \mathrm{HR}, 0.193 ; 95 \%$ CI, 0.094-0.511 for Livin and PIGF) (Table III). These results suggested that high Livin and PlGF expression are independent prognostic factor for OS in patients with osteosarcoma.

\section{Discussion}

With the development of neoadjuvant chemotherapy, the long-term survival of patients with osteosarcoma of the extremity without metastatic disease has improved from $10-15 \%$ to $50-70 \%$ (18). However, patients with metastatic disease at diagnosis exhibit a poor prognosis due to chemotherapy resistance. Resistance to chemotherapy is a hallmark of osteosarcoma (19). The reduction of anti-apoptotic factors may provide a rational basis for the development of novel therapeutic strategies target in cancer osteosarcoma (20). IAPs are the only known endogenous proteins that regulate the activity of initiator and effector caspases (21). Overexpression of XIAP and survivin has been identified in osteosarcoma, indicating that IAP-mediated inhibition of apoptosis may participate in tumorigenesis (21). Livin is one of the novel human IAP family members, which was first described in melanoma. It has been demonstrated that Livin was expressed in a number of types of tumor cell and several fetal tissues, but not in normal adult tissues. Livin is not detectable in the majority of types of normal differentiated tissue, with the exception of the placenta, testes, spinal cord and lymph node; however, it is present in a number of types of cancer including carcinomas of the breast and prostate, osteosarcoma, melanoma and lymphoma cells (21).

A previous study revealed that Livin antagonized the death receptor and mitochondria-based apoptosis signaling pathways via the inhibition of downstream caspases including caspase-3, caspase-7 and caspase-9, leading to their inactivation and degradation (22). The anti-apoptotic potential of Livin and its preferential expression in osteosarcoma, at very low or undetectable levels in the corresponding normal tissue, suggest that the manipulation of Livin expression could represent a novel and tumor-specific molecular target for cancer therapy (23). Zhuang et al (24) demonstrated that long-term silencing of Livin expression inhibited the proliferation of Livin-expressing non small-cell lung cancer cells and increased the chemosensitivity of NSCLC cells.

Consistent with a previous study (25), the results of the present study identified that a substantial proportion of primary osteosarcoma tissues expressed Livin (58.3\%) and the positive expression of Livin was significantly associated with advanced staged osteosarcoma. In the present study, the expression levels of Livin in the osteosarcoma specimens were significantly increased, compared with those in normal bone tissue. The high expression of Livin was significantly associated with OS, clinical Enneking stage and tumor diameter, but not with other clinicopathological factors. Livin expression levels in patients exhibiting stages I-IIA were significantly decreased, compared with those in patients exhibiting stages IIB-III. In addition, analysis of the 5-year OS rate identified a significant difference between patients with osteosarcoma in the Livin positive-expression group and patients who did not express Livin. Livin was primarily identified as a granular pattern in the cytoplasm in the present study. Additionally, the gene expression of Livin was determined in three different osteosarcoma cell lines (SaOS-2, MG-63 and U2OS) and identified to be increased in MG-63 cells, compared with that in the two other cell lines. Therefore, the results of the present study demonstrated that Livin may serve a function in osteosarcoma development, which is similar to the findings of a previous report, which identified the function of Livin in other types of malignancy (26).

A previous study demonstrated that angiogenesis serves a key function in cancer growth, and was regarded as a marker for invasiveness and metastasis in osteosarcoma (27). VEGF has been extensively studied and is considered to be the most important pro-angiogenic factor in osteosarcoma (28). PlGF, which exhibits $42 \%$ amino acid sequence identity with VEGF, was initially cloned from the placenta and cooperated with VEGF in the formation of vasculature (29). A previous study has demonstrated the prognostic implication of high PlGF expression in a number of types of cancer (30). PlGF serves a key function in tumor angiogenesis by affecting endothelial cells via VEGF receptor (VEGFR)-1 (31). Actions of PIGF in tumor angiogenesis include the following: Separating VEGF from VEGFR-1, enabling VEGF to activate VEGFR-2; acting as 
Table III. Multivariate analysis of Livin and PlGF expression for the prognosis of osteosarcoma.

\begin{tabular}{lccc}
\hline Variables & HR & P-value & $95 \%$ CI \\
\hline Livin high expression & 0.274 & 0.023 & $0.089-0.839$ \\
PlGF high expression & 0.209 & 0.014 & $0.060-0.728$ \\
Livin and PIGF high expression & 0.001 & 0.193 & $0.094-0.511$
\end{tabular}

Livin, baculoviral IAP repeat containing 7; PIGF, placental growth factor; HR, hazard ratio; CI, confidence interval.

a stimulator via binding to VEGFR-1, which in turn would increase cell sensitivity to VEGF acting via VEGFR-2; recruiting monocytes/macrophages, which affects vessel growth; and mobilizing hematopoietic progenitor cells from the bone marrow (31). Previous studies have demonstrated that increased PIGF expression was associated with tumor progression and the invasiveness of cancer cells was inhibited by the anti-PIGF antibody $(32,33)$. However, the level of PIGF protein expression and its significance in osteosarcoma remain unknown.

To the best or our knowledge, the present study was the first study to quantitate the PlGF expression in human osteosarcoma tissues and cell lines in order to evaluate the association between PlGF expression and the prognosis of osteosarcoma. The results of the present study revealed that positive expression of PIGF is significantly associated with advanced tumor stage and a tumor diameter $>5 \mathrm{~cm}$. Increased expression of PIGF was observed in advanced stage osteosarcoma, compared with that in early stage osteosarcoma, and high PIGF expression was indicative of a poor prognosis for the patient. The results of the present study validated that PIGF was significantly upregulated in osteosarcoma specimens, compared with that in normal bone tissues. In addition, the association between PIGF and prognosis was of increased significance in stage IIB-III patients, compared with that in stage IB-IIA patients. The results of the present study indicated that PlGF may not be involved in the early development and growth of osteosarcoma. The effect of Livin and PIGF expression was additionally studied in three human osteosarcoma cell lines. MG-63, an osteoblast-derived osteosarcoma cell line derived from a 14-year-old Caucasian male, is considered to be representative of osteoblast precursors or early undifferentiated osteoblast-like cells (34). SaOS-2 is a non-transformed osteoblast-like cell line derived from the primary osteosarcoma of an 11-year-old Caucasian female (35) and U2OS was derived from a moderately differentiated sarcoma of the tibia of a 15-year-old female (36). The expression levels of Livin and PIGF in MG-63 cells were markedly increased, compared with those in U2OS and SaOS-2 cell lines; this result may be because MG-63 cells are phenotypically more differentiated than U2OS and SaOS-2 cells $(37,38)$. Therefore, it has been suggested by the present study that PlGF may serve a function in the rapid restoration of tumor blood supply following treatment and thus may enhance the possibility of cancer recurrence. PIGF may be a therapeutic target in patients with cancer recurrence. 

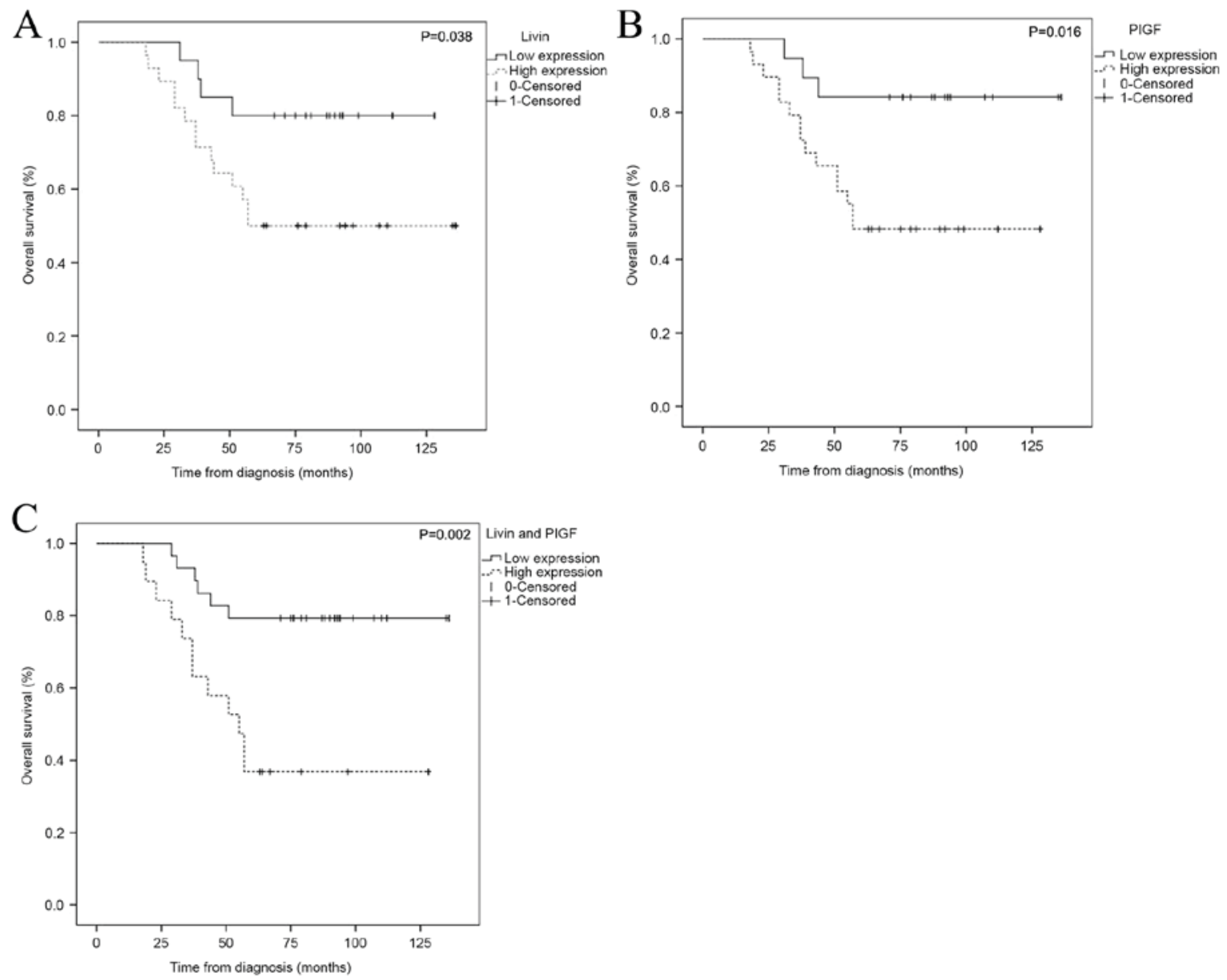

Figure 3. Kaplan-Meier estimator survival curves for patients with osteosarcoma according to the expression of Livin and PIGF. (A) Livin high expression predicted a decreased overall survival $(\mathrm{P}=0.038)$. (B) PIGF high expression predicted a decreased overall survival ( $\mathrm{P}=0.016)$. (C) High expression of Livin and PIGF predicted a decreased overall survival $(\mathrm{P}=0.002)$. The dashed line represents positive expression of Livin or/and PIGF, while the solid line represents negative expression of Livin or/and PIGF. Livin, baculoviral IAP repeat containing 7; PIGF, placental growth factor.

The present study has demonstrated that Livin is positively expressed in osteosarcoma and may be an important prognostic marker for the survival of patients with osteosarcoma. In addition, the results of the present study revealed that increased levels of PIGF are significantly associated with poorly differentiated osteosarcoma and a poor outcome for the patient. Anti-angiogenic therapy exhibits potential in combination with conventional chemotherapy for patients with osteosarcoma and additional studies are required to validate this. Therefore, the present study identified that Livin and PlGF may be potential treatment targets for human osteosarcoma. However, as the size of the present sample is limited, additional validation is required.

\section{Acknowledgements}

Not applicable.

\section{Funding}

The present study was supported by the National Natural Science Foundation of China (grant no. 81660443), the Natural Science Foundation of Jiangxi Province (grant no. 20122BBG70107-3) and the Foundation of Shanghai Health Bureau (grant no. 2010061).

\section{Availability of data and materials}

All data generated or analyzed during this study are included in this published article.

\section{Authors' contributions}

KS conducted the molecular genetic studies, participated in the sequence alignment performed the statistical analysis and drafted the manuscript. ZC performed the immunoassays. TC participated in the design of the study. JZ and QL conceived the study, participated in its design and coordination and assisted in drafting the manuscript. All authors read and approved the final manuscript.

\section{Ethics approval and consent to participate}

The present study was approved by the ethical committee of Zhongshan Hospital, Fudan University and had been performed in accordance with the ethical standards laid down in the 1964 Declaration of Helsinki. Due to the present study being retrospective, the ethics committee specifically approved that not informed consent was required due to data being analyzed anonymously; therefore, informed consent was not required, 
but the patients or their guardians signed in informed consent for the surgery.

\section{Patient consent for publication}

All of the patients or their guardians signed informed consent for the publication of the present study.

\section{Competing interests}

The authors declare that they have no competing interests.

\section{References}

1. Pruksakorn D, Phanphaisarn A, Pongnikorn D, Daoprasert K, Teeyakasem P, Chaiyawat P, Katruang N and Settakorn J: Age standardized incidence rates and survival of osteosarcoma in northern thailand. Asian Pac J Cancer Prev 17: 3455-3458, 2016.

2. Aznab M and Hematti M: Evaluation of clinical process in osteosarcoma patients treated with chemotherapy including cisplatin adriamycin, ifosfamide, and etoposide and determination of the treatment sequels in a long-term 11-year follow-up. J Cancer Res Ther 13: 291-296, 2017.

3. PosthumaDeBoer J, Witlox MA, Kaspers GJ and van Royen BJ: Molecular alterations as target for therapy in metastatic osteosarcoma: A review of literature. Clin Exp Metastasis 28: 493-503, 2011

4. Du MD, He KY, Qin G, Chen J and Li JY: Adriamycin resistance-associated prohibitin gene inhibits proliferation of human osteosarcoma MG63 cells by interacting with oncogenes and tumor suppressor genes. Oncol Lett 12: 1994-2000, 2016.

5. Yoon TM, Kim SA, Lee DH, Lee JK, Park YL, Lee KH, Chung IJ, Joo YE and Lim SC: Livin enhances chemoresistance in head and neck squamous cell carcinoma. Oncol Rep 37: 3667-3673, 2017.

6. Li CJ, Cong Y, Liu XZ, Zhou X, Shi X, Wu SJ, Zhou GX and Lu M: Research progress on the livin gene and osteosarcomas. Asian Pac J Cancer Prev 15: 8577-8579, 2014.

7. Hou Q, Li MY, Huang WT, Wei FF, Peng JP, Lou MW and Qiu JG Association between three VEGF polymorphisms and renal cell carcinoma susceptibility: A meta-analysis. Oncotarget 8: 50061-50070, 2017.

8. Liang L, Yue Z, Du W, Li Y, Tao H, Wang D, Wang R, Huang Z, He N, Xie X, et al: Molecular imaging of inducible VEGF expression and tumor progression in a breast cancer model. Cell Physiol Biochem 42: 407-415, 2017.

9. Yan B, Kong M, Chen S and Chen YH: VEGF stimulation enhances Livin protein synthesis through mTOR signaling. J Cell Biochem 111: 1114-1124, 2010.

10. Chen L, Ren GS, Li F and Sun SQ: Expression of livin and vascular endothelial growth factor in different clinical stages of human esophageal carcinoma. World J Gastroenterol 14: 5749-5754, 2008.

11. Pagani E, Ruffini F, Antonini Cappellini GC, Scoppola A, Fortes C, Marchetti P, Graziani G, D'Atri S and Lacal PM: Placenta grow th factor and neuropilin-1 collaborate in promoting melanoma aggressiveness. Int J Oncol 48: 1581-1589, 2016.

12. Babkina IV, Osipov DA, Solovyov YN, Bulycheva IV, Machak GN, Aliev MD and Kushlinsky NE: Endostatin, placental growth factor, and fibroblast growth factors- 1 and -2 in the sera of patients with primary osteosarcomas. Bull Exp Biol Med 148: 246-249, 2009.

13. Marrony S, Bassilana F, Seuwen K and Keller H: Bone morphogenetic protein 2 induces placental growth factor in mesenchymal stem cells. Bone 33: 426-433, 2003

14. Mahmoodi F and Akrami H: PlGF knockdown decreases tumorigenicity and stemness properties of spheroid body cells derived from gastric cancer cells. J Cell Biochem 118: 851-859, 2017.

15. Incio J, Tam J, Rahbari NN, Suboj P, McManus DT, Chin SM, Vardam TD, Batista A, Babykutty S, Jung K, et al: PIGF/VEGFR-1 signaling promotes macrophage polarization and accelerated tumor progression in obesity. Clin Cancer Res 22: 2993-3004, 2016.

16. Enneking WF, Spanier SS and Goodman MA: A system for the surgical staging of musculoskeletal sarcoma. Clin Orthop Relat Res: 106-120, 1980.

17. Kawasaki H, Altieri DC, Lu CD, Toyoda M, Tenjo T and Tanigawa N: Inhibition of apoptosis by survivin predicts shorter survival rates in colorectal cancer. Cancer Res 58: 5071-5074, 1998
18. Wang YF, Shen JN, Xie XB, Wang J and Huang G: Expression change of ezrin as a prognostic factor in primary osteosarcoma. Med Oncol 28(Suppl 1): S636-S643, 2011.

19. Sampson VB, Vetter NS, Zhang W, Patil PU, Mason RW, George E, Gorlick R and Kolb EA: Integrating mechanisms of response and resistance against the tubulin binding agent Eribulin in preclinical models of osteosarcoma. Oncotarget 7: 86594-86607, 2016.

20. Horie R, Nakamura O, Yamagami Y, Mori M, Nishimura H, Fukuoka N and Yamamoto T: Apoptosis and antitumor effects induced by the combination of an mTOR inhibitor and an autophagy inhibitor in human osteosarcoma MG63 cells. Int J Oncol 48: 37-44, 2016.

21. Saleem M, Qadir MI, Perveen N, Ahmad B, Saleem U, Irshad T and Ahmad B: Inhibitors of apoptotic proteins: New targets for anticancer therapy. Chem Biol Drug Des 82: 243-251, 2013.

22. Liu GH, Wang C and Ding ZY: Overexpression of the truncated form of Livin reveals a complex interaction with caspase-3. Int J Oncol 42: 2037-2045, 2013.

23. Lin X, Li HR, Lin XF, Yu ME, Tu XW, Hua ZD, Lin M, Xu NL, Han LL and Chen YS: Silencing of Livin inhibits tumorigenesis and metastasis via VEGF and MMPs pathway in lung cancer. Int J Oncol 47: 657-667, 2015 .

24. Zhuang L, Shen LD, Li K, Yang RX, Zhang QY, Chen Y, Gao CL, Dong $\mathrm{C}, \mathrm{Bi} \mathrm{Q}$, Tao JN, et al: Inhibition of livin expression suppresses cell proliferation and enhances chemosensitivity to cisplatin in human lung adenocarcinoma cells. Mol Med Rep 12: $547-552,2015$.

25. Nedelcu T, Kubista B, Koller A, Sulzbacher I, Mosberger I, Arrich F, Trieb K,Kotz R and Toma CD:Livin and Bcl-2 expression in high-grade osteosarcoma. J Cancer Res Clin Oncol 134: 237-244, 2008.

26. Guan HP, Sun JZ, Feng XL, Chen JS, Chen FJ, Cheng XF, Liu XW and Ni B: Effects of RNA interference-mediated knockdown of livin and survivin using monomethoxypolyethylene glycol-chitosan nanoparticles in MG-63 osteosarcoma cells. Mol Med Rep 13: 1821-1826, 2015.

27. Ségaliny AI, Mohamadi A, Dizier B, Lokajczyk A, Brion R, Lanel R, Amiaud J, Charrier C, Boisson-Vidal C and Heymann D: Interleukin-34 promotes tumor progression and metastatic process in osteosarcoma through induction of angiogenesis and macrophage recruitment. Int J Cancer 137: 73-85, 2015.

28. Liu JQ, Bai X, Duan DC and Dou AX: Role of five small nucleotide polymorphisms in the VEGF gene on the susceptibility to osteosarcoma and overall survival of patients. Oncol Lett 10: 1481-1486, 2015.

29. Autiero M, Waltenberger J, Communi D, Kranz A, Moons L, Lambrechts D, Kroll J, Plaisance S, De Mol M, Bono F, et al: Role of PIGF in the intra- and intermolecular cross talk between the VEGF receptors Flt1 and Flk1. Nat Med 9: 936-943, 2003.

30. Ribatti D: The discovery of the placental growth factor and its role in angiogenesis: A historical review. Angiogenesis 11: 215-221, 2008.

31. Fischer C, Jonckx B, Mazzone M,Zacchigna S, Loges S, Pattarini L, Chorianopoulos E, Liesenborghs L, Koch M, De Mol M, et al: Anti-PlGF inhibits growth of VEGF(R)-inhibitor resistant tumors without affecting healthy vessels. Cell 131: 463-475, 2007.

32. Meng FJ, Xiao SX, Zhang Y, Wang W, Wang B and Fan XY: Prognostic significance of placenta growth factor expression in patients with multiple cancers: A meta-analysis. Int J Clin Exp Med 8: 12726-12735, 2015.

33. Taylor AP and Goldenberg DM: Role of placenta growth factor in malignancy and evidence that an antagonistic PlGF/Flt-1 peptide inhibits the growth and metastasis of human breast cancer xenografts. Mol Cancer Ther 6: 524-531, 2007.

34. Clover J and Gowen M: Are MG-63 and HOS TE85 human osteosarcoma cell lines representative models of the osteoblastic phenotype? Bone 15: 585-591, 1994.

35. Fogh J, Wright WC and Loveless JD: Absence of HeLa cell contamination in 169 cell lines derived from human tumors. J Natl Cancer Inst 58: 209-214, 1977.

36. Pontén J and Saksela E: Two established in vitro cell lines from human mesenchymal tumours. Int J Cancer 2: 434-447, 1967.

37. Lisignoli G, Toneguzzi S, Cattini L, Pozzi C and Facchini A: Different expression pattern of cytokine receptors by human osteosarcoma cell lines. Int J Oncol 12: 899-903, 1998.

38. Cifuentes M, García MA, Arrabal PM, Martínez F, Yañez MJ, Jara N, Weil B, Domínguez D, Medina RA and Nualart F: Insulin regulates GLUT1-mediated glucose transport in MG-63 human osteosarcoma cells. J Cell Physiol 226: 1425-1432, 2011.

This work is licensed under a Creative Commons Attribution-NonCommercial-NoDerivatives 4.0 International (CC BY-NC-ND 4.0) License. 